\title{
Case study: A systems analysis of cattle morbidity in a niche market beef cooperative
}

\author{
Kim McCuistion, ${ }^{1 *}$ Jen Johnson Livsey, ${ }^{1}$ Doug Wilmeth, ${ }^{1}$ Dan Probert, ${ }^{2}$ Barry Dunn, ${ }^{3}$ \\ Ryan Rhoades, ${ }^{1}$ and Clay Mathis ${ }^{1}$
}

Submitted 18 February 2011 / Accepted 25 May 2011 / Published online 7 November 2011

Citation: McCuistion, K., Livsey, J. J., Wilmeth, D., Probert, D., Dunn, B., Rhoades, R., \& Mathis, C. (2011). Case study: A systems analysis of cattle morbidity in a niche market beef cooperative. Journal of Agriculture, Food Systems, and Community Development, 2(1), 279-286. http://dx.doi.org/10.5304/jafscd.2011.021.011

Copyright (C) 2011 by New Leaf Associates, Inc.

\begin{abstract}
Country Natural Beef (CNB) is a rancher-owned, niche market beef cooperative. In fall 2008, CNB experienced an increase in cattle morbidity at the feedlot. With a reduced number of animals qualifying for the CNB program, the possibility of being unable to meet customer demand became a critical concern. Consequently, CNB proactively initiated an internal investigation to identify the underlying reasons and key risk factors that contributed to the increase in morbidity. An analysis was conducted to determine size and scope of the problem,
\end{abstract}

\footnotetext{
${ }^{1}$ King Ranch Institute for Ranch Management, Texas A\&M University-Kingsville, Kingsville, TX 78363 USA

${ }^{2}$ Country Natural Beef, Boardman, OR 97818 USA

${ }^{3}$ South Dakota State University, College of Agriculture and Biological Sciences, Brookings, SD 57007 USA

* Corresponding author: Kim McCuistion, 700 University Boulevard, MSC 137, Kingsville, TX 78363 USA; +1-361-593-3690; kim.mccuistion@tamuk.edu
}

identify key risk factors, and provide recommendations for supply chain improvement. A sample of $42 \mathrm{CNB}$ member ranchers, $\mathrm{CNB}$ employees, and personnel from the feedlot where CNB cattle are finished were interviewed to provide a better understanding of the ranchers' behavior, production chain structures, management protocols, and company policies. Recommendations to reduce morbidity rates included: (1) background all cattle, (2) institute internal process controls to include auditing the accounts at regular intervals, and (3) amend the policies that allow the shift in financial responsibility of morbidity from individual ranchers to the organization as a whole. Implementing these recommendations should minimize feedlot morbidity in the CNB program and make the program more viable in the marketplace by reducing fluctuations in supply. Similar niche beef production programs should consider their entire production chain in order to maintain a balance between the demand and supply and minimize the cost of production. 


\section{Keywords}

animal health, niche beef production, producer cooperative, supply chain

\section{Introduction}

Previous studies have indicated that American consumers are concerned about food safety (Caswell, 1998). Since 2000, consumer confidence in beef safety has remained relatively stable, ranging from $60 \%$ to $91 \%$ (McCarty, 2010). Beef consumers are most concerned with microbial load of the product and pesticide use to control parasites, followed by hormone and antibiotic treatments (McCarty, 2010). This suggests that beef consumers want information about animal production practices to base purchasing decisions on; consequently, additional niche markets that focus on food production practices have been created. The USDA regulates food product labels as "natural," "no hormones," "no antibiotics," or "organic" (USDA, 2010). Although demand for these niche market products has slowed during the recent economic downturn, it is expected that natural and organic products will grow at a rate of $13 \%$ and 7\%, respectively, between 2010 and 2017 as the economy recovers (Nutrition Business Journal, 2010). Sales of this broad category of foods increased by $1.8 \%$ during 2009 , exceeding US $\$ 143$ billion in sales (Nutrition Business Journal, 2010). These general trends suggest that some consumers are more aware of the way their foods are produced and are willing to pay a premium for foods that are produced in a manner that they perceive to be a healthy and ecologically sustainable.

Country Natural Beef (CNB) is a rancher-owned cooperative with its headquarters in Oregon and with member ranches in Arizona, California, Colorado, Hawaii, Idaho, Montana, Nevada, New Mexico, North Dakota, Oregon, Texas, Washington, and Wyoming (www.coutrynatural beef.com). $\mathrm{CNB}$ was formed as a beef marketing cooperative in 1986 by 14 families who had a vision of protecting ranchlands and preserving rural family culture by directly linking ranchers and consumers. $\mathrm{CNB}$ cattle are raised in a humane manner (as certified by third-party auditors), are never fed animal-derived feedstuffs, and never receive antibiotics or hormones. Therefore, CNB cattle supply beef to a niche market.

Beef from animals that become sick and receive therapeutic antibiotics no longer qualify for some niche markets that CNB supplies. Consequently, antibiotic treated animals would be removed from the program. During the third quarter of 2008, the number of cattle removed from the program due to sickness (referred to in cattle production as morbidity) increased to $7.3 \%$, a three-fold increase over the previous four-year average of $2.4 \%$. Morbidity increased CNB's production costs for 2008 and had the potential to disrupt the CNB beef supply chain. With a reduced number of animals qualifying for the CNB program, there was a possibility that supply would not meet consumer demand. This led CNB upper management to initiate an internal investigation to identify the underlying reasons and key risk factors that contributed to the increase in morbidity. This introspection would assist in identifying the weaknesses of the present system, thus repairing and rejuvenating the system to live up to the expectations of customers in the future.

\section{Country Natural Beef Supply Chain}

It is mandatory for the ranchers in the CNB program to own and raise cattle from birth. For the first 12 to 18 months after birth, cattle from member ranches are raised on native range, seeded pastures, and hay meadows. To ensure a continuous supply of feeder cattle throughout the year, some ranchers use winter grow lots and feed a ration usually based on silage, hay, and corn before shipping cattle to the BeefNorthWest (BNW) feedlot. CNB member ranches are audited by the authorities of Food Alliance, a national nonprofit organization that certifies sustainable agricultural practices.

All cattle in the $\mathrm{CNB}$ program are finished at the BNW feedlot in Boardman, Oregon. The cattle arrive at BNW weighing approximately $800 \mathrm{lbs}$. $(363 \mathrm{~kg})$ and finish weighing between 1,100 lbs. and 1,300 lbs. (499 and $590 \mathrm{~kg}$ ) (D. Probert of CNB, personal communication, March, 2009). The 
cattle are fed for 90 days, in comparison to the industry average of 150 to 180 days (Muth et al., 2005). Cattle are fed a $100 \%$ vegetarian diet. To comply with CNB protocols, antibiotics and ionophores are not added to the rations, and cattle are not implanted with growth hormones. Careful visual observations of live cattle are used to sort cattle for slaughter. Each ranch is individually responsible for feed, yardage, and processing fees incurred by their lots of cattle (W. Killion of BNW, personal communication, March 2009).

Cattle in the CNB program are humanely slaughtered and fabricated into retail cuts and ground beef products at a beef packing plant in Toppenish, Washington. Cattle are slaughtered on a weekly basis. Those carcasses that meet the CNB criteria for meat quality and yield grade are sorted and selected for fabrication. The beef is then packaged and sold as CNB beef in retail stores such as Whole Foods and New Seasons and in restaurants such as Burgerville.

\section{Current Organization Structure}

Each CNB member ranch holds a seat on the board of directors and has one vote. A management team is elected annually and consists of nine CNB members. A chairman and vice chairman are elected from the management team members. Three teams, the marketing and sales team, the financial team, and the production team, are in charge of different aspects of CNB operations.

CNB's marketing team maintains the relationships with CNB's retail customers and also develops new products. The marketing team maintains the $\mathrm{CNB}$ website, creates promotional materials, and facilitates in-store demonstrations to develop the relationship between meat cutters and consumers. The team is responsible for filling weekly customer orders and maintaining the meat inventory balance. This team is also responsible for scheduling cattle on feed at the BNW feedlot. Scheduling occurs 18 months prior to the actual slaughter date to maintain proper supply inventories and flow of cattle from birth to finish.

CNB's financial team handles all accounts payable, accounts receivable, and payments to ranchers. Additionally, it maintains all carcass and profitability data for individual ranches and the entire CNB cooperative.

CNB's production team schedules and manages the flow of cattle from member ranches to the BNW feedlot. The production team works closely with the marketing team and the feedlot to schedule and make any necessary adjustments to cattle entering and leaving the feedlot at the correct weight and time while also meeting retail customer demands for inventory. Other duties include coordinating new member recruitment, ensuring age and source verification, and fielding member questions and concerns. This team also generates a CNB newsletter and ensures that insurance needs are fulfilled.

\section{Applied Research Methods}

An assessment tool was developed and delivered via personal interview to determine if management practices on $\mathrm{CNB}$ member ranches affected morbidity levels in the feedlot. There were $117 \mathrm{mem}$ bers in the CNB cooperative. Sixty ranchers were randomly selected to be interviewed; only 42 members participated in the project. Eighty-eight percent of these ranchers were from Oregon. Each rancher was asked the same questions regarding ranch location, cattle health, nutrition, genetics, and general management practices. Rancher interviews were conducted both in person $(\mathrm{n}=21)$ and telephonically $(n=21)$ in February and March 2009. Information obtained through the interview process was used to identify potential risk factors that could affect cattle health. Management and staff at $\mathrm{CNB}$ and $\mathrm{BNW}$ were also interviewed to provide an understanding of the production chain process after cattle leave the ranch. The study protocol was approved by the university's Institutional Review Board.

Data for all CNB member ranches between 2004 and 2008 was compiled to evaluate morbidity levels in the feedlot. This data consisted of a rancher's lot number, number of head per lot, date the lot entered the feedlot, and the number of morbid cattle per lot. Morbidity levels ranged from $0 \%$ to $56 \%$, with a standard deviation of $7 \%$. Information 
obtained through the interview process was combined with this CNB data set.

Based on the interview, health management information was categorized into two topics, backgrounding method and vaccination protocol, and incorporated with the five-year data set. Backgrounding refers to management practices that are designed to enhance the immune system, improve nutritional status, and reduce post-weaning stress of calves. This is achieved through confining newly weaned calves to an enclosed space and exposing them to eating out of bunks. For this study, cattle were categorized into three different backgrounding protocols consisting of (1) no backgrounding — cattle go straight from weaning to grass; (2) backgrounding for approximately 45 days, then turning out to grass; and (3) backgrounding on the ranch or in a custom background yard for approximately 45 days, then going straight to the feedlot. Cattle in each of the three methods were raised to approximately 800 lbs., taken to BNW for finishing, and slaughtered approximately 90 days later when they weighed between 1,100 and 1,300 lbs. Cattle were also categorized based on vaccination protocol prior to entering the feedlot. Cattle were classified as not vaccinated ( 0 vaccinations) or vaccinated (1 or more vaccinations). The experimental unit was lot of cattle. Each lot contained numerous cattle that were used to calculate percent morbidity per lot.

A generalized linear model was used to evaluate morbidity levels for the entire CNB program between 2004 and 2008. A similar generalized linear model was used to analyze the effect backgrounding method and vaccination protocols had on morbidity of the cattle at the interviewed ranchers. Year and quarter were included in the model to determine if year and/or season affected cattle sickness. The generalized linear model with logistical regression for binomial counts was performed using Pearson's chi-square and adjusted for overdispersion.

\section{Results and Discussion}

\section{Overall Morbidity}

The results from 2004 through 2008 indicate that a total of 216,325 head of cattle went through CNB's program. The total number of sick cattle during this five-year period was 6,277 head. The average morbidity rate was $2.9 \%$, which is much lower than both the national average of $15 \%$ (Nixon, 2007) and the conventional BNW cattle, which had a range of $15 \%$ to $18 \%$ morbidity (W. Killion, Boardman, Oregon, personal communication, February 2009). The morbidity rate of CNB cattle indicate that management practices of $\mathrm{CNB}$ ranchers are better than those of average ranchers.

The results obtained during the third quarter of 2008 indicates an increase in morbidity to $7.3 \%$ from a previous four-year third quarter average of $2.4 \%$, which garnered the attention of $\mathrm{CNB}$

\section{Figure 1. Country Natural Beef Morbidity Levels (sick, \%) by Quarter for the Years 2004 to 2008 and a Five-year Average by Quarter}

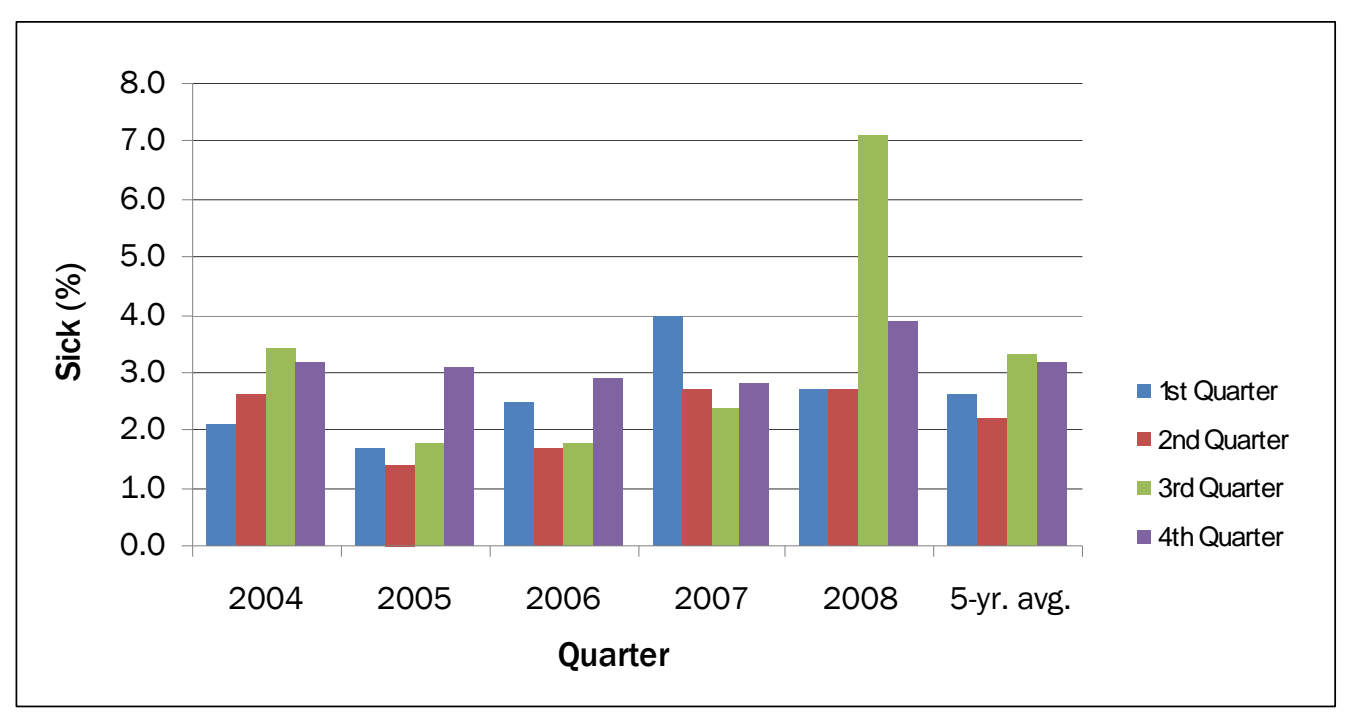


leadership (figure 1). Upon investigation, one explanation for this finding was that the feedlot, BNW, had a two-week delay in processing newly received cattle (W. Killion, Boardman, Oregon, personal communication, February 2009). Under normal circumstances, cattle were processed within a 24-hour period upon arrival at the feedlot. The backlog in processing caused a delay in the incoming cattle receiving their vaccinations in a timely manner. This delay may have put cattle at risk for morbidity due to being commingled and exposed to pathogens without the proper immunity obtained through vaccination. Typical feedlot receiving protocols recommend vaccination within 48 hours of arrival; however, recent literature states that there is no production loss or economic cost associated with a delay in vaccination (Richeson et al., 2008).

It is also important to note that there was an interaction between year and quarter $(\mathrm{P}<0.01)$ for cattle morbidity; this was likely due to uncontrollable variables, such as climate and weather.

Interviewed Ranchers. The 42 ranchers accounted for 972 lots and 120,379 head of cattle, which constituted over half of the CNB program cattle between 2004 and 2008. The total number of sick cattle among the 972 lots was 3,568 head. The overall morbidity level of cattle from these observations was $3.0 \%$, indicating the morbidity level of the sample was representative of the cattle fed in the program between 2004 and 2008 (table 1).

Cattle backgrounded for approximately 45 days and then returned to grass had a $56 \%$ lower chance of being sick than cattle not backgrounded after weaning and sent straight to grass $\left(X_{1}{ }^{2}=36.18, \mathrm{P}<\right.$ 0.01). Likewise, cattle that were backgrounded on the ranch or in a custom yard post-weaning and sent straight to the feedlot had a 39\% lower chance of being sick than cattle that were not backgrounded $\left(X_{1}^{2}=19.13, \mathrm{P}<0.01\right)$. Reduced levels of morbidity are seen with backgrounded cattle because they were trained to eat from a bunk, were confined and exposed to other animals, and acquire immunity through exposure (D.

Grotelueschen, Phizer, Gering, Nebraska, personal communication, April 2009). Upon arrival to the feedlot, cattle that have been backgrounded are not naïve to their new environment. Results from this study support the need for backgrounding approximately 45 days to reduce morbidity in the feedlot.

Recommended vaccination procedures for ranchers include an initial vaccination followed by a booster at weaning and 2 to 4 weeks post-weaning. Although the literature strongly supports the efficacy of vaccination programs (Duff \& Galyean, 2007), in this study there was no difference in morbidity between cattle that did and did not receive vaccines $(\mathrm{P}>0.20)$ prior to arrival at the feedlot. Because only one rancher chose not to vaccinate, a statistical significance could not be detected in this study due to the small sample size.

Cost. If CNB cattle became sick enough to require treatment with antibiotics, they were removed from their original lot, treated for the illness, commingled in a separate pen, and given a new lot number.

Table 1. Summary of Country Natural Beef (CNB) Program Cattle Morbidity Between 2004 and 2008

\begin{tabular}{lcrrr}
\hline & & \multicolumn{3}{c}{ Interviewed Ranchers } \\
\cline { 3 - 5 } & All CNB cattle & No background & $\begin{array}{c}\text { Background, } \\
\text { then grass }\end{array}$ & $\begin{array}{c}\text { Background, } \\
\text { then feedlot }\end{array}$ \\
\hline Number of lots & 2,188 & 271 & 358 & 343 \\
\hline Number of cattle & 216,325 & 36,993 & 38,211 & 45,175 \\
\hline Number of sick cattle & 6,277 & 1,269 & 981 & 1,318 \\
\hline Percent Morbidity & 2.9 & 3.4 & 2.6 & 2.9 \\
\hline
\end{tabular}


Because these animals were treated with antibiotics, they no longer qualified for the CNB program. Thus, these cattle were finished in a traditional manner (including nontherapeutic antibiotics, ionophores, and growth promoting implants) and marketed conventionally. To separate costs, a new lot number (Lot 9000) was formed. When cattle were taken out of the CNB program and put into Lot $9000, \mathrm{CNB}$ purchased the cattle from the ranch owner based on a discounted conventional market price. The loss for cattle in Lot 9000 ranged from $\$ 26$ to $\$ 338$ per head. In addition to medication costs, morbidity in feedlot cattle likely reduced profitability due to lower rates of gain and a decrease in carcass quality (Gardner, Dolezal, Bryant, Owens, \& Smith, 1999; Roeber et al., 2001). The total loss attributed to Lot 9000 cattle for the 2008 fiscal year was US $\$ 215,000$. This was an average of US $\$ 200$ per sick animal. When this loss was distributed over the healthy cattle, it cost each member an average US $\$ 5.00$ per head to cover the financial loss associated with morbid cattle.

Through the interview process, it was evident that individual ranchers generally assumed that if their cattle were healthy when they left their ranch, sickness at the feedlot was a result of mismanagement further down the production line. When sickness occurred, ranchers often called the production office and $\mathrm{CNB}$ management team to discuss problems and potential solutions that would result in healthier cattle at the feedlot. Organizationally, CNB's response to increased morbidity was to form investigative committees charged with finding solutions, such as the development of Lot 9000 . These solutions, guided by the unwritten rule that $\mathrm{CNB}$ takes care of its members and helps each other with problems, shifted the cost of morbidity from individual ranchers to the organization as a whole.

The CNB member ranches and BNW joined together for a win-win partnership, but the increased morbidity caused the partners to view themselves as isolated adversaries rather than parts of a whole functioning system. Though not organizationwide or true of all members, this viewpoint began to infiltrate discussions, further impeding progress to find causes and solutions relevant to the entire production chain.

\section{Process Verified Observations}

The interview process revealed no evidence of standardized process verified control measures in place for CNB suppliers of cattle to the BNW feedlot. Though Food Alliance does audit member ranches for safe and fair working conditions, humane animal treatment, and environment-related practices, no internal or external audits existed for any standardized management protocols. Likewise, there was no whole herd disease testing, record of adherence to beef quality assurance guidelines, supplier training, or evidence of membership record-keeping. $\mathrm{CNB}$ recommended that members use an approved list of vaccines and one of two vaccination protocols, but there was no evidence these protocols were followed.

\section{Recommendations}

Recommendation 1: Background Cattle for at Least 45 Days. Previous cattle morbidity research indicates that a major risk factor is backgrounding length and method. Cattle backgrounded for 45 days or greater have consistently shown lower levels of morbidity (Mathis, Loest, \& Carter, 2008). Cattle that were backgrounded for 45 days or greater (on ranch or custom background yard) before being turned out on grass were less likely to become sick than cattle not backgrounded or backgrounded for less than 45 days before being turned out to grass. The results of this study indicate that ranchers who do not background cattle further increase the risk of morbidity in those cattle further down the production chain.

\section{Recommendation 2: Implement a Process Control and Verification Program. This control system would measure, analyze, and maintain benchmarks and standard operating procedures to increase producer efficiency and provide a tool to improve morbidity numbers. Personnel at the feedlot would receive documentation from each ranch stating the backgrounding program and vaccination protocol followed. Process verification within the supply}


chain would help reduce variation in the health status of the cattle supply. Likewise, benchmarks for the feedlot should be established to ensure cattle are processed in a timely manner, which would prevent instances of backlog like that which occurred in the fall of 2008.

Process verified control programs in the agriculture industry have increased in recent years (USDA, 2009). Independent companies offer services that provide third-party audits, training, and verification of process control or claims of product attributes. Third-party verification enables companies to ensure product claims and compliance to potential consumers; thus, third-party audits should increase product marketability due to customer confidence in the product. A program with control limits, corrective actions, penalties, and removal procedures for continuous noncompliance would ensure that the quality of $\mathrm{CNB}$ products and standards are maintained.

Recommendation 3: Allocate Morbidity Costs Directly to the Ranch of Origin. Shifting the financial burden of morbidity from CNB back to individual ranchers would incentivize on-ranch behaviors that minimize the risk of morbidity later in the production chain. Animals should be individually identified when moved from the CNB program to a traditional feeding program. Thus, instead of spreading the cost of sick animals in Lot 9000 over the entire $\mathrm{CNB}$ membership, treatment costs and lost productivity of individual animals could be allocated directly to the ranch of origin.

\section{Conclusion}

It is especially important for niche market programs to be aware of production costs. Beef products that qualify for some niche markets must forego efficiency-enhancing technologies used in traditional production, such as the use of nontherapeutic antibiotics, growth-promoting implants, ionophores, and $\beta$-agonists. In addition, sick cattle treated with therapeutic antibiotics no longer qualify for programs such as the CNB program; consequently, minimizing morbidity at the feedlot is especially important for CNB. Similar niche beef production programs must take into account the problems that may be encountered along the entire production chain in order to maintain supply, meet market demand, and keep production costs low. In this study, steps suggested to help CNB minimize morbidity include backgrounding cattle for at least 45 days, implementing a process verification program, and allocating morbidity costs to individual ranchers instead of the organization as a whole. Implementation of these recommendations should minimize feedlot morbidity in the CNB program and make the program more viable in the marketplace by reducing fluctuations in supply.

\section{References}

Caswell, J. A. (1998). How labeling of safety and process attributes affects markets for food. Agricultural and Resource Economics Review, 27(2), 151-158. http://purl.umn.edu/31517

Duff, G. C., \& Galyean, M. L. (2007). Board-Invited Review: Recent advances in management of highly stressed, newly received feedlot cattle. Journal of Animal Science, 85, 823-840. http://dx.doi.org/ $10.2527 /$ jas.2006-501

Gardner, B. A., Dolezal, H. G., Bryant, L. K., Owens, F. N., \& Smith, R. A. (1999). Health of finishing steers: Effects on performance, carcass traits, and meat tenderness. Journal of Animal Science, 77(12), 3168-3175.

Mathis, C. P., Loest, C. A., \& Carter, B. (2008). Preconditioning beef calves. Circular 637. New Mexico State University Extension.

McCarty, R. (2010). Consumer perceptions of beef safety: Research overview. Research Report. National Cattlemens Beef Association.

Muth, M. K., Brester, G., Roccili, J. D., Koontz, S., Martin, B., Piggot, N., Taylor, J. , Vukina, T., \& Wohlgenant, M. (2005, July). Spot and alternative marketing arrangements in the livestock and meat industries (interim report). Research Triangle Park, North Carolina: RTI International. http://www.meatami. $\mathrm{com} / \mathrm{ht} / \mathrm{a} /$ GetDocumentAction/i/2461

Nixon, L. (2007). Exploring natural. Beef Magazine. http://beefmagazine.com/mag/beef_exploring natural/index.html

Nutrition Business Journal. (2010). NBJ's 2010 Healthy Foods Report. Retrieved from http://lib.store.yahoo. net/lib/nbj/10hfreptoc.pdf 
Richeson, J. T., Beck, P. A., Gadberry, M. S., Gunter, S. A., Hess, T. W., Hubbell III, D. S., \& Jones, C. (2008). Effects of on-arrival versus delayed modified live virus vaccination on health, performance, and serum infectious bovine rhinotracheitis titers of newly received beef calves. Journal of Animal Science, 86, 999-1005. http://dx.doi.org/10.2527/jas.2007-0593

Roeber, D. L., Speer, N. C., Gentry, J. G., Tatum, J. D., Smith, C. D., Wittier, J. C., Jones, G. F., Belk, K. E., \& Smith, G. C. (2001). Feeder cattle health management: Effects on morbidity rates, feedlot performance, carcass characteristics, and beef palatability. The Professional Animal Scientist, 17, 39-44.
United States Department of Agriculture (USDA). (2009). Official listing of approved USD A process verified programs. Retrieved March 2009 from http://www.ams.usda.gov/AMSv1.0/ getfile?dDocName $=$ STELPRD 3320450

United States Department of Agriculture (USDA). (2010). Meat and poultry labeling terms. Retrieved from http://www.fsis.usda.gov/factsheets/ Meat \& Poultry Labeling_Terms/index.asp 